\title{
Experimental Research on Damage Parameter of Concrete in Non-Uniform Stress Field
}

\author{
Aimin Deng', Daoyuan $\mathrm{Xu}^{1}$ \\ ${ }^{1}$ Department of Engineering Mechanics, Hohai University, Nanjing, China \\ E-mail:d-a-m@sohu.com \\ Received April 8, 2011; revised May 9, 2011; accepted May 18, 2011
}

\begin{abstract}
The damage variables of describing the material damage state should be chosen first when the research of concrete structures by use of theory of damage theory. The method of calculation of damage parameter by the measure of the change of the elastic modulus of concrete specimens is effectively. In this paper, the wedge splitting tests with double bearing of three groups of different initial crack lengths of concrete specimens were conducted, and the stress and the strain of the points with different distance from the initial crack tip measured and calculated, and the damage value with peak stress of the various points were calculated based on the stress-strain curves. From the results of the test, the damage parameter can be confirmed under the non-uniform stress field, and the initial crack length has some influence on the damage parameter, and the longer the initial crack length and the greater the damage parameter.
\end{abstract}

Keywords: Non-Uniform Stress Field, Wedge Splitting Experiment, Damage Parameter, Crack Length

\section{Introduction}

Concrete is one of the main materials of buildings such as the traffic, civil, hydraulic, etc. Because it is a multiphase particulate composite, during the process of pouring and molding, a variety of defects in concrete could not be avoided. Moreover, the interfaces are relatively weak, and micro cracks may occur here [1]. Although these defects and micro cracks may be discontinuous and random, but when a concrete structure is subjected to the external loads, temperature changes, chemicals and so on, these micro cracks and defects may develop and some new micro-cracks will appear, through the collection, connectivity and result in macro cracks. If the continuing role of external factors, this process will not only continue to occur, but also may cause instability propagation of the macro crack in concrete, and the safe operation of concrete structures must be endangered [2].

Generally, the causes of failure of concrete structures are often diverse and multiple, but the failure is always caused by the germination and propagation of cracks. From the point of view of damage mechanics, initial defects and micro-cracks is a type of damage, the germination and propagation of cracks are the process of the accumulation of damage. In recent years, many scholars had researched the fracture failure process of concrete structures based on the theory of damage mechanics, and a large number of valuable results are made.

In the analysis of the mechanical characteristics of concrete material with the theory of damage mechanics, the appropriate damage variables to describe the material damage state must be chosen firstly. The macroscopic physical properties of material will changes because of the damage. So, many experts determine the degree of damage by the changes of elastic modulus of material based on the strain equivalence principle, that is the degree of damage calculated by the determination of changes of elastic modulus of concrete specimens [3-5]. In this paper, based on the concrete wedge splitting tests with 3 different initial crack length, the stresses and strain of points with three different distances to the crack tip had been measured and calculated, and the damage values corresponding peak stress of the points were calculated according to stress-strain curves. From the test results can be seen, damage parameters can also be determined in non-uniform stress field, and the initial crack length have a certain extent influence on the damage parameters, the longer the initial crack length the greater the damage value. 


\section{Overview of Concrete Wedge Splitting Tests}

All concrete specimens are cast with the same materials and the same mix proportion of 1:1.5:2.5:0.4 (cement: sand: aggregate: water: wt.) with the maximum aggregate size of $20 \mathrm{~mm}$ and ordinary building sand and are tested 28 days after they were made. The specimen dimensions are $200 \times 200 \times 200 \mathrm{~mm}^{3}$, the initial preformed crack length $a_{0}$ are $80 \mathrm{~mm}, 100 \mathrm{~mm}$ and $120 \mathrm{~mm}$, and the specimen geometry and loading methods used are shown in Figure 1. Tests are all conducted with $200 \mathrm{kN}$ Electronic Universal Testing Machine. The loading forces are controlled by displacement in computer, and the load and displacement are measured by the force sensor and displacement sensor directly connected to the computer. To test the changes of elastic modulus of materials in damaged area and calculate the damage parameters of specimens, the strain gauges with $5 \mathrm{~cm}$ long connected with the strain instrument are affixed symmetrically on both sides of the ligament of specimens distances from preformed crack tip $1 \mathrm{~cm}, 3 \mathrm{~cm}, 5 \mathrm{~cm}$.

The cube compressive strength of the concrete material $f_{c u}$ is $26.8 \mathrm{MPa}$, the splitting tensile strength $f_{t}$ is 2.3 $\mathrm{MPa}$, the modulus of elasticity $E_{c}$ is $32.7 \mathrm{GPa}$, and the Poisson's ratio $\mu$ is 0.174 .

\section{The Results and Calculations of Tests}

According to the force analysis of wedge under the load (Figure 2), the following formulas can be obtained

$$
\begin{gathered}
p=2 \times p_{\mathrm{v}} \times \sin 15^{\circ} \\
p_{\mathrm{h}}=p_{\mathrm{v}} \times \cos 15^{\circ} \\
\text { so } p_{\mathrm{h}}=p / 2 \tan 15^{\circ}
\end{gathered}
$$

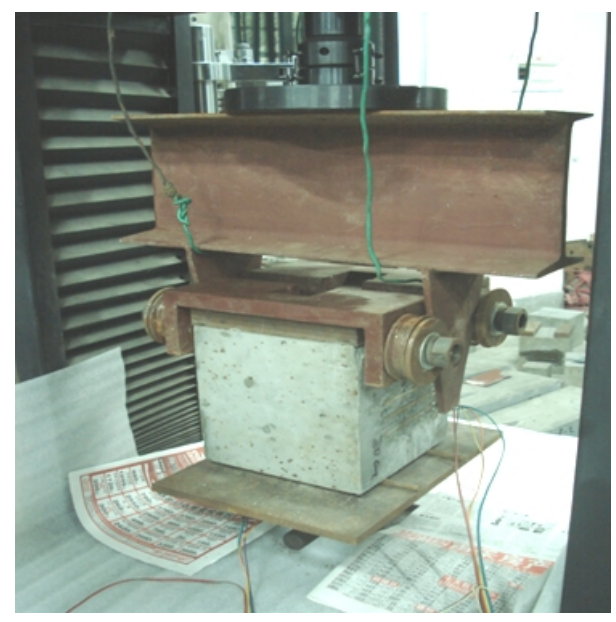

Figure 1. Concrete specimens and wedge splitting test.

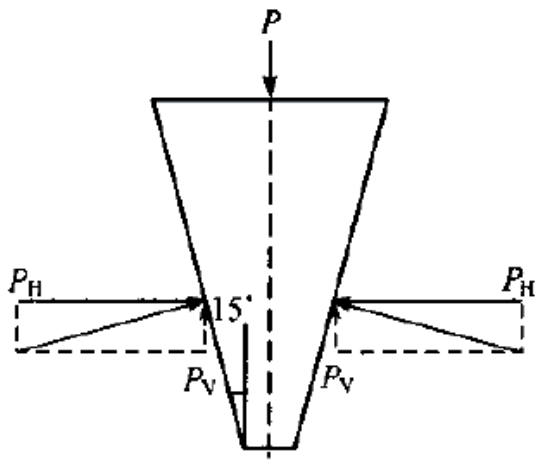

Figure 2. Force analysis of loading wedge.

Based on the stress formula of combined deformation with tension and bending, the stresses of the points at the specimen ligament can be calculated by following formula

$$
\sigma=\frac{p_{\mathrm{H}}}{A}+\frac{12 M_{\mathrm{H}} \cdot y}{b h^{3}}
$$

Where $b$ is the thickness of the specimen, $h$ is the height of the specimen ligament, $y$ is the distance from strain gauge to the neutral axis, $A$ is the area of the ligament regional, $M_{H}$ is the moment generated by $p_{H}$ [6].

According to the results of testing and calculation, the stress-strain curves are plotted, and the typical stressstrain curve shown in Figure 3. Based on the linear phase of stress-strain curve, the elastic modulus $E$ can be calculated, and the elastic modulus corresponding to peak stress of damage material can be calculated by the peak point of the curve, and the damage value of this point is the value of damage corresponding to the peak stress, and determined by following formula

$$
D_{f}=1-\bar{E} / E
$$

The results of calculation of the 3 groups specimens are given in Table 1.

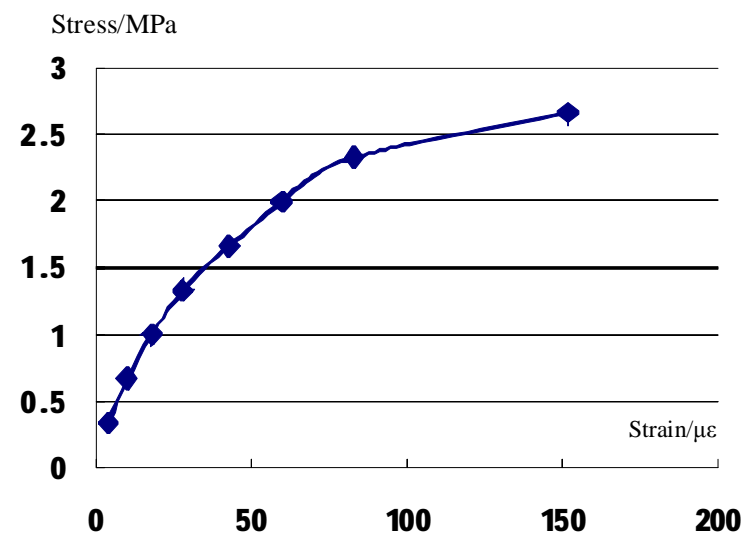

Figure 3. The typical stress-strain curve. 
Table 1. Results of calculation of the 3 groups specimens.

\begin{tabular}{ccccc}
\hline$a_{0} / \mathrm{cm}$ & Distance/cm & $\begin{array}{c}\text { Elastic Modulus } \\
\text { of Damage } \\
\text { Material } \bar{E} / \mathrm{GPa}\end{array}$ & $\begin{array}{c}\text { Elastic } \\
\text { Modulus } \\
E / \mathrm{GPa}\end{array}$ & $\begin{array}{c}\text { Damage } \\
\text { Value } D_{f}\end{array}$ \\
\hline \multirow{2}{*}{8} & 1 & 21.12 & 33.12 & 0.36 \\
& 3 & 25.02 & & 0.24 \\
10 & 1 & 21.45 & 36.18 & 0.41 \\
& 3 & 28.88 & & 0.20 \\
12 & 1 & 21.60 & 39.39 & 0.45 \\
& 3 & 30.83 & & 0.22 \\
\hline
\end{tabular}

\section{Analysis of the Test Results}

1) During the loading process, the tensile strain of the various points within $3 \mathrm{~cm}$ distance to the crack tip continue to increase with the increase of the load until the fracture of the specimen. The complete ascending phase of the stress-strain curve tests can be determined, and the damage value of the points can be calculated according to the curve. The strain of the points distance to the crack tip $5 \mathrm{~cm}$ outside in the specimens with $8 \mathrm{~cm}$ and $10 \mathrm{~cm}$ length pre-crack are compressive strain in the beginning load phase, a small tensile strain will occur until the specimen fracture, while in the specimens with $12 \mathrm{~cm}$ length pre-crack, the strain of these points have been to compressive strain. This shows that, the area of the damage zone in crack tip relatives to the length of the pre-crack in the fracture failure of concrete specimens, and there is a compressive stress region in the ligament area of specimens. In a range of pre-crack length cases, the compressive stress region may be a certain size, and it also indicates that pre-crack length does not affect the fracture mechanical properties of concrete specimens.

2) The damage area of these specimens more than $3 \mathrm{~cm}$, and the greater value of damage corresponding to the peak stress the closer distance to the tip of the pre-crack. It indicates that, the damage in the region of the closer distance to the tip of the pre-crack is more obvious during the failure process of the specimens, and in the non-uniform stress field, the damage value corresponding to the peak stress may be related to the stress gradient of the stress field.

3) According to the results of measure of strain and calculation of the value of $D_{f}$ of these points which distance closer to pre-crack tip of the 3 groups specimens we can see, the damage value $D_{f}$ corresponding to the peak stress is obvious increase with the pre-crack length increases, it shows that the stress gradient of the stress field related to the pre-crack length, and the longer pre-crack length the bigger stress gradient.

\section{Conclusions}

The measure of damage parameters of concrete by fracture tests of concrete is an important part of the study of concrete damage. In this paper, based on three groups concrete wedge splitting tests of different initial crack lengths specimens, the damage values $D_{f}$ of concrete materials corresponding to the peak stress are measured and Calculated under non-uniform stress field. According to the results of measured and Calculated, the method of measuring damage parameters under non-uniform stress field is feasible. The extent of damage of the area more closer to the tip of the pre-crack is more obvious in the failure process of specimen, and the initial crack length has some impact on the damage parameters, it shows that in the non-uniform stress field, the damage value corresponding to the peak stress may be related to the stress gradient of the stress field.

\section{Acknowledgements}

This work is supported by the National Nature Science Foundation of China (Nos.10972072 and 50878077).

\section{References}

[1] T. Q. Yu and J. C. Qian, "Damage Theory and Its Application," National Defence and Engineering Press, Beijing, 1993.

[2] X. D. Wang, D. Y. Xu, W. X. Zhu and A. M. Deng, "Damage of Concrete Dams and Its Simulation Calculation," Key Engineering Materials, Vol. 302-303, 2006, pp. 624-629. doi:10.4028/www.scientific.net/KEM.302-303.624

[3] L. Qiu, D. Y. Xu, W. X. Zhu and A. M. Deng, "Study of Initial Damage and Damage Development of Concrete by Compression Test," Journal of Hefei University of Technology (Nature Sciences), Vol. 24, No. 6, 2001, pp. 10611065.

[4] A. M. Deng and D. Y. Xu, "Experimental Research on the Damage of Concrete by Uniaxial Tension," Journal of Hefei University of Technology (Nature Sciences), Vol. 26, No. 1, 2003, pp. 77-80.

[5] X. D. Wang, A. M. Deng and Y. F. Wang, "Experiment Study on Size Effect of Concrete Compress Damage Parameters," Key Engineering Materials, Vol. 452-453, 2011, pp. 349-352. doi:10.4028/www.scientific.net/KEM.452-453.349

[6] M. L. Huang and X. D. Wang, "Effect of Support Forms on Fracture Toughness $K_{\text {I C }}$ of Wedge Splitting Specimens," Journal of Hohai University (Natural Sciences), Vol. 34, No. 4, 2006, pp. 435-439. 